JUURNAL

of Health Inequalities

\title{
Alcohol consumption by pregnant women in Poland
}

\author{
Cezary Wojtyła', Andrzej Wojtyła² \\ 'First Department of Obstetrics and Gynaecology, Centre of Postgraduate Medical Education, Wasaw, Poland \\ ${ }^{2}$ Higher Vocational State School in Kalisz, Poland
}

\begin{abstract}
Introduction: Alcohol consumption during pregnancy has a negative impact on the developing foetus from the earliest stages of its development. It increases the risk of miscarriage, intrauterine death and congenital abnormalities. It contributes to the development of mental retardation and may also lead to physical, cognitive and behavioural abnormalities. The aim of this study was to evaluate the frequency and amount of alcohol consumed by women in Poland during the preimplantation and pregnancy periods.

Material and methods: Analyses of pregnant women in Poland were based on surveys within the framework of Polish Pregnancy-related Assessment Monitoring System. The research was conducted on one specific day in 2010, 2011 and 2012 in all the hospitals in Poland where women were staying following childbirth, and was in the nature of a population study.

Results: Among the surveyed women, 54.7\% declared that they consumed alcohol during pregnancy, while $45.3 \%$ declared abstinence. More than $35 \%$ of the women consuming alcohol during pregnancy consumed it once a month or less frequently. Almost $6 \%$ of them consumed alcohol at least 2 times a month during pregnancy. More than $60 \%$ of the women who consumed alcohol during pregnancy consumed less than one standard unit of alcohol on one occasion. Almost $20 \%$ consumed at least one standard unit of alcohol on one occasion.

Conclusions: The percentage of women who consume alcohol during the preimplantation period is over $90 \%$. Also more than half of women consume alcohol during pregnancy. These behaviours pose a substantial risk to the embryo, especially at its earliest stage of development.
\end{abstract}

KEY WORDS: alcohol consumption, pregnancy, foetal alcohol syndrome, foetal alcohol spectrum disorder.

ADDRESS FOR CORRESPONDENCE: Cezary Wojtyła, First Department of Obstetrics and Gynaecology, Centre of Postgraduate Medical Education, 231 Czerniakowska Street, 00-416 Warsaw, Poland, e-mail: czwo@op.pl

\section{INTRODUCTION}

Alcohol consumption among pregnant women is associated with many adverse obstetric outcomes. Alcohol negatively affects both mother and child. It is one of the major risk factors with regard to the growth and development of the foetus. It contributes to the development of mental retardation and may also lead to physical, cognitive and behavioural abnormalities in children, which together are called Foetal Alcohol Spectrum Disorder (FASD) [1,2]. The risk of its occurrence increases with the amount of alcohol consumed during pregnancy [3]. In order to assess the actual amount of alcohol consumed, the term "standard unit of alcohol" was introduced, i.e. the amount of pure ethanol consumed. This is defined as $10 \mathrm{~g}$ of pure ethanol [4]. $285 \mathrm{ml}$ of beer with an alcoholic strength of $4.8 \%$ contains one standard unit of alcohol and the same applies to $100 \mathrm{ml}$ of wine and $30 \mathrm{ml}$ of vodka [5].

Alcohol passes through the placental barrier to the foetus's bloodstream. Its concentration in the foetal body exceeds that in the mother's body, due to slower metabolism. The liver of the foetus is not fully developed, which means a slower synthesis of alcohol dehydrogenase by hepatocytes. It is estimated that the activity of this enzyme, at approximately 20 weeks of gestation, is about half that in an adult [6]. Both ethanol and acetaldehyde enter the amniotic fluid, which further hinders their elimination from the foetal environment [7]. It is 
worth mentioning here that acetaldehyde is a recognized mutagen [8].

Ethanol has a negative effect on the embryo from the earliest moments of its development. It appears that the embryo is particularly sensitive to the effects of alcohol during preimplantation and gastrulation periods [9]. However, the preimplantation period is also considered key to its future functioning [9]. Further stages of foetal development involve intense cell differentiation. At this stage, alcohol consumption can also have negative effects on the foetus. Ethanol affects the methionine homocysteine cycle, and therefore DNA methylation and gene expression [10-14].

At every stage of embryonic and foetal development, alcohol consumption can have negative consequences. Alcohol negatively affects the foetus not only during the first weeks of pregnancy. Consumption of ethanol in the third trimester of pregnancy can lead to damage to the hippocampus, resulting in among other things memory disorders $[15,16]$.

The whole range of foetal development disorders resulting from a foetus's exposure to alcohol consumed by its mother is termed foetal alcohol spectrum disorder (FASD). Among others, this group includes [17]:

- foetal alcohol syndrome (FAS),

- alcohol-related neurodevelopment disorder (ARND),

- alcohol-related birth defects and developmental disorders (ARBD).

The occurrence of respective forms of FASD is determined not only by the dose of ethanol consumed but also by duration of exposure [9]. The most easily diagnosed variation of FASD is FAS. According to the Centers for Disease Control and Prevention (CDC), its prevalence in the United States is between 0.2 and 1.5 cases per 1,000 live births [17]. This level is comparable to the prevalence of Down syndrome or spina bifida [18]. FAS is the most serious of the syndromes described to date resulting from chronic consumption of high doses of alcohol during pregnancy [19]. There exist four basic criteria for identifying this syndrome: specific craniofacial anomalies, growth disorders, central nervous system disorders, and evidence of alcohol consumption during pregnancy [17]. There are no criteria for diagnosing FAS in the prenatal period. Although ultrasound diagnostic may suggests the existence of a syndrome, a definitive diagnosis cannot be determined on this basis alone [20] Certain diagnose may only be confirmed after a baby is born. Dissection analyses of babies born to women who drink alcohol during pregnancy provide data on changes in the central nervous system caused by alcohol. These children are characterized by agenesis of the corpus callosum, changes in the area of the brainstem, hippocampus, cerebellum and pineal gland [21,22]. These changes cause, among other things, memory, concentration and learning disorders. In addition to the above, it has been observed that children with the FAS also suffer from intellectual development and psychomotor disorders as well as social adaptation inadequacies [22].

Other syndromes associated with FASD are more frequently found than FAS. Their occurrence is usually associated with less severe foetal exposure to alcohol, but in order to identify them, it is necessary to connect symptoms with the fact of ethanol consumption during pregnancy. These include ARND and ARBD. ARND is characterized by structural changes in the foetal brain, similar to those that characterize FAS, as well as behavioural and developmental changes in the child. On the other hand, ARBD are diagnosed in children with two or more of the craniofacial anomalies that characterize FAS, and at least one other developmental defect involving the kidneys, heart, musculoskeletal system, hearing or vision $[2,23]$.

The aim of the study was to evaluate the frequency and amount of alcohol consumed by women in the preimplantation period and during pregnancy in Poland.

\section{MATERIAL AND METHODS}

Analyses of the population of pregnant women in Poland were carried out using survey questionnaires within the framework of the Polish Pregnancy-related Assessment Monitoring System (Pol-PrAMS). The questionnaire was based on a survey used in the USA for Pregnancy Risk Assessment Monitoring Survey (PRAMS) [24].

The research was conducted between 2010 and 2012 as a population study. It was conducted annually, in different months of the year, in order to obtain a representative test group. This was because it was assumed that the number of births may fluctuate seasonally. The study was conducted on a group of Polish women and their newborns, in all hospitals in Poland in which women following childbirth were staying along with their newborns.

The survey questionnaires were addressed to women convalescing postpartum in hospitals that had at least one of the following wards: Maternity, Gynaecology and Obstetrics, Rooming-in Maternity, Neonatal or a Childbirth Room. The study was conducted on a nationwide basis. The purpose was to assess the health related behaviour of pregnant women in Poland, such as their physical activity, diet and its supplements, smoking and consumption of alcohol and psychoactive substances, as well as to assess the course of their pregnancies, the birth and the condition of both newborns and mothers after childbirth.

The survey's questionnaire was divided into two parts. The first section contained information about the pregnant subjects such as age, place of residence, education, marital status, social status, obstetric history (previous births, miscarriages, and any difficulties with becoming pregnant), and any behaviour by the mother before and during pregnancy constituting a health risk (smoking, alcohol consumption, drugs or psychoactive substances). 
The section of the survey's questionnaire concerning alcohol consumption during pregnancy included a request for information on the prevalence of alcohol consumption before and during pregnancy, the amount of standard drinks consumed during any one occasion, the type of alcohol consumed, and the attending physician's attitude to alcohol being consumed during pregnancy. The first part of the form was completed by mothers who, along with their newborn babies, remained in hospital after childbirth. The second section was completed by the specialized medical staff (doctor, nurse) responsible for taking care of the mother and newborn after childbirth, citing the subject's medical documentation.

In total, 9051 women with newborn babies qualified for inclusion in this analysis in 2010-2012. During the study period, the questionnaire was filled out by 8625 mothers, constituting $95.3 \%$ that were thus analyzed statistically. These were women who answered at least one of the survey questions. They represented $76.9 \%$ of the total number of women in obstetrics wards in Poland at that time.

The methodology of this study is described in detail in a separate article [25].

\section{RESULTS}

Of all the women surveyed, $91.2 \%$ declared they had consumed alcohol in the three months before their pregnancy, while $8.8 \%$ declared abstinence. On becoming pregnant, the percentage of women drinking alcohol decreased to $54.7 \%$. Thus, $45.3 \%$ of the women declared that they had not consumed alcohol during pregnancy (Table 1).
Before becoming pregnant, $56.1 \%$ of the women consumed alcohol once a month or less often, and at the same time constituted $61.5 \%$ of the women who consumed alcohol during pregnancy. Less than one in four women (24.4\%) declared that they consumed alcohol 2-4 times a month (constituting $26.8 \%$ of the women who declared having drunk alcohol during pregnancy); while those declaring that they consumed alcohol 2-3 times a week and 4 times a week or more constituted 5.8\% (6.4\%) and $1.8 \%(2.0 \%)$ respectively. These behaviours changed during pregnancy. The group of women who consumed alcohol once a month or less frequently decreased to $19.6 \%$, while the group of women who consumed alcoholic beverages 2-4 times a month decreased to $2.1 \%$. The above groups accounted for $35.9 \%$ and $3.8 \%$ of women consuming alcohol during pregnancy. Additionally, $0.4 \%$ of women declared that they consumed alcohol 2-3 times a week. These accounted for $0.8 \%$ of women who admitted to drinking alcohol during pregnancy. The figures for the group of women who consumed alcohol 4 or more times a week, which amounted to $0.8 \%$ (1.5\%) during pregnancy, also declined. Also observed was a significant increase in the proportion of women who did not specify the frequency of alcohol consumption during pregnancy. This proportion before pregnancy was $3.1 \%$, while during pregnancy the figure increased to $31.8 \%$. Table 2 shows the prevalence of alcohol consumption by women before and during pregnancy.

More than $40 \%$ of women in the preimplantation period consumed 1 to 2 standard units of alcohol on one occasion. Less than $13 \%$ of them consumed less than one standard unit of alcohol. Larger amounts: 3-6 and at least

TABLE 1. Alcohol consumption by women before and during pregnancy

\begin{tabular}{|l|c|c|c|c|}
\hline \multirow{2}{*}{} & \multicolumn{2}{|c|}{ Before pregnancy } & \multicolumn{2}{c|}{ During pregnancy } \\
\cline { 2 - 5 } & Number & $\%$ & Number & $\%$ \\
\hline Consumed alcohol & 3369 & 91.2 & 1374 & 54.7 \\
\hline Did not consume alcohol & 326 & 8.8 & 1139 & 45.3 \\
\hline Total & 3695 & 100.0 & 2513 & 100.0 \\
\hline
\end{tabular}

TABLE 2. Frequency of alcohol consumption by women before and during pregnancy

\begin{tabular}{|l|c|c|c|c|c|c|}
\hline \multirow{2}{*}{} & \multicolumn{4}{|c|}{ Before pregnancy } & \multicolumn{3}{c|}{ During pregnancy } \\
\cline { 2 - 7 } & Number & $\%$ of all & $\begin{array}{c}\text { \% of women } \\
\text { consumed alcohol }\end{array}$ & Number & \% of all & $\begin{array}{c}\text { \% of women } \\
\text { consumed alcohol }\end{array}$ \\
\hline Did not report & 113 & 3.1 & 3.3 & 798 & 31.8 & 58.0 \\
\hline Did not consume & 326 & 8.8 & - & 1139 & 45.3 & - \\
\hline Once a month or less & 2073 & 56.1 & 61.5 & 493 & 19.6 & 35.9 \\
\hline 2-4 times a month & 902 & 24.4 & 26.8 & 52 & 2.1 & 3.8 \\
\hline 2-3 times a week & 215 & 5.8 & 6.4 & 11 & 0.4 & 0.8 \\
\hline 4 or more times a week & 66 & 1.8 & 2.0 & 20 & 0.8 & 1.5 \\
\hline Total & 3695 & 100.0 & 100.0 & 2513 & 100.0 & 100.0 \\
\hline
\end{tabular}


TABLE 3. The amount of standard units of alcohol consumed by pregnant women at a time

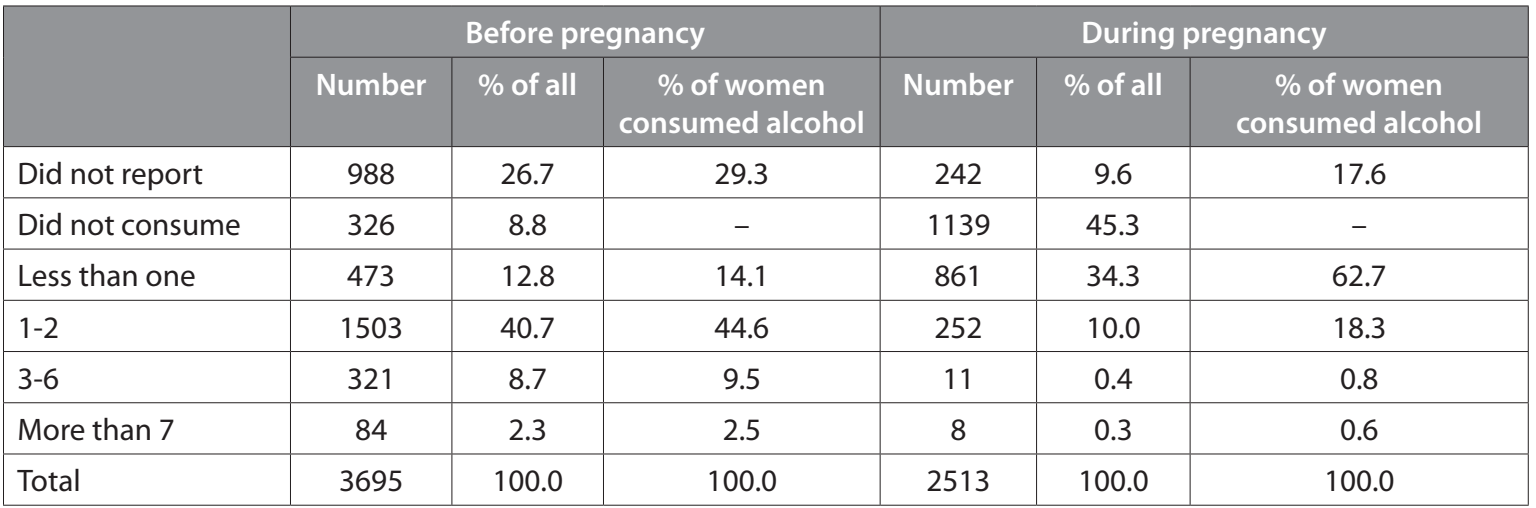

7 standard units were consumed by $8.7 \%$ and $2.3 \%$ of women respectively. Taking into account only women who consumed alcohol before pregnancy, these percentages were: $44.6 \%, 14.1 \%, 9.5 \%$ and $2.5 \%$, respectively. Almost $35 \%$ of pregnant women consumed less than 1 standard unit of alcohol at a time; $10.0 \%$ consumed 1-2 standard units of alcohol at a time, whereas 3-6 and 7 or more units were consumed by $0.4 \%$ and $0.3 \%$ of pregnant women respectively. Taking into consideration only women who consumed alcohol during pregnancy, these amounted to $62.7 \%, 18.3 \%, 0.8 \%, 0.6 \%$, respectively. The percentage of women who reported having consumed alcohol during pregnancy but who did not admit the amount they consumed at a time was $9.6 \%$. This percentage before pregnancy was $26.7 \%$ (Table 3 ).

Fragmented data on the consumption of alcohol by pregnant women in Poland, based on Pol-PrAMS studies, has been presented in separate publications $[26,27]$.

\section{DISCUSSION}

In a study conducted in the United States by Ebrahim et al. [28] in 1999, more than half of women of reproductive age drank alcohol during the last month. Most of them declared occasional drinking. Nevertheless, $15 \%$ of them can be classified as drinking moderately or significantly $[29,30]$. Almost the same number of respondents declared binge drinking at least once in the last month [31]. In our study the percentage of women consuming alcohol in the preimplantation period is much higher. A little over $90 \%$ of women claimed to have consumed alcohol in the three months prior to becoming pregnant.

The percentage of women who consume alcohol during pregnancy varies considerably in different countries around the world. In the United States, the percentage of women who abstain from drinking alcohol during pregnancy has increased slightly from year to year. However, $13 \%$ continue to consume alcohol during this period of their lives [31]. In Italy $30 \%$ of pregnant women declare that they consume alcohol daily [32]. The same research also indicates that pregnancy is not seen by Italian wom- en as a reason to stop drinking alcohol. In South Korea, the proportion of pregnant women drinking alcohol is $16 \%$ [33]. Studies conducted in Denmark show that almost half of women became inebriated at least once during the menstrual cycle in which fertilization took place $[34,35]$. Alcohol consumption in some Eastern European countries is even higher. In a study conducted in Russia, $85 \%$ of pregnant women drank alcohol during pregnancy, and $20 \%$ declared binge drinking at least once during that time [36]. In Poland, according to a study conducted by the State Agency for Solving Alcohol Problems (PARPA), 12\% of pregnant women declared that they drank alcohol during pregnancy [37]. According to a 2007 report by the United Nations Population Fund (UNFPA), the United Nations Development Program (UNDP) and Poland's Ministry of Health, 12-17\% of women in Poland consume alcohol during pregnancy $[37,38]$. However, it would seem that the above figures for Poland are greatly underestimated, as it is clear from our study that over half of women consumed alcohol during pregnancy.

The data show that the highest proportion of pregnant women in Poland (8.5\%) consumed alcohol only a few times during their entire pregnancy [38]. Daily consumption of alcoholic beverages was declared by $0.4 \%$, several times a month by $0.8 \%$, once a month by $1.5 \%$, and once during the entire pregnancy by $4.1 \%$, whereas $1.2 \%$ of women do not remember if and how often they consumed alcohol during their pregnancy [38]. The alcoholic beverage most often consumed by pregnant women was beer. Its consumption was declared by $45 \%$ of women drinking alcohol during pregnancy; $42 \%$ of women consumed wine and less than $8 \%$ consumed vodka [38]. According to Ethan et al. [39] in the United States, $30.3 \%$ of women consume alcohol during pregnancy; $5.7 \%$ of them drank at least 5 drinks or more on one occasion; $26 \%$ of American women consumed wine, $21.9 \%$ drank beer, $15.7 \%$ consumed a variety of drinks, and $4.2 \%$ drank strong spirits [39].

Our study indicates that most pregnant women who admit to consuming alcohol during pregnancy con- 
sumed it once a month or less frequently. This may suggests that these women consumed alcoholic beverages while unaware that they were pregnant. Thus, over $6 \%$ of women consuming alcohol continued to do so during pregnancy. It should be stressed however, that the proportion of women who reported having consumed alcohol during pregnancy, but not the frequency of doing so was $58 \%$, which may indicate the poor credibility of the results obtained. The respondents probably consumed alcohol during pregnancy more frequently than ensues from the data obtained. Among women who consumed alcohol during pregnancy, $62.7 \%$ consumed less than one standard unit of alcohol, but almost $20 \%$ consumed at least one standard unit on one occasion. These data are not complete, as indicated by the $17 \%$ of respondents who did not report the number of standard units of alcohol consumed at one time.

The above evidence shows that the problem of alcohol consumption by women in the preimplantation period and during pregnancy is much more serious than the data previously collected suggest. The proportion of women who consume alcohol during pregnancy is significantly higher, and does not amount to $12-17 \%$ [37, 38 ], but almost $55 \%$, of which $6.1 \%$ consume alcohol at least twice a month throughout their pregnancy. Of course, changing patterns of alcohol consumption have been observed. Women consume it in smaller amounts than before pregnancy.

Another problem is the consumption of alcohol by women before becoming pregnant. If after childbirth more than $90 \%$ of women declared alcohol consumption before becoming pregnant, $12 \%$ of whom reported consuming at least 3 standard units of alcohol at a time, this begs the question how many women in Poland have had miscarriages due to alcohol consumed before they found out they were pregnant. The consumption of $60 \mathrm{~g}$ of ethanol once a week increases the risk of miscarriage fourfold and the risk of intrauterine foetal death threefold [40, 41]. Consuming of just $20 \mathrm{~g}$ of ethanol leads to disorders in the breathing movements of the foetus [42].

The answer to this question seems even more worrying, when we consider the age at which Polish teenagers begin consuming alcohol, because studies have found that among girls the average age they start drinking alcohol is 13.54 and the average age they first become inebriated is 14.35 . This data is very similar to the figures for boys beginning alcohol consumption and becoming inebriated for the first time (13.33 and 14.18 respectively) [43]. The same studies show that the percentage of girls who start drinking between the ages of 11 and 15 is dramatically increasing. More than $85 \%$ of 11 -yearold girls declare that they do not consume alcohol. That percentage at age 13 is only $61.2 \%$, and at the age of 15 it is already a mere $31 \%$. True, in recent years the frequency with which Polish teenagers drink alcohol and get drunk has declined, but at the same time girls are getting drunk more often and at an earlier age. This is a very disturbing phenomenon, as it forms dangerous habits and the wrong attitude towards drinking by young girls and future mothers. Such a high prevalence of alcohol consumption among women entering reproductive age poses an enormous risk of adverse pregnancy outcomes in the future. It should be strongly emphasized that there is no known "safe" dose of alcohol that would not cause foetal development disorders. For this reason, women who are or may be pregnant should avoid consumption of alcohol [3].

\section{CONCLUSIONS}

Recent studies show that previous data on the consumption of alcohol by pregnant women in Poland are underestimated. More than half of women consume alcohol during pregnancy, and not as previously believed only $12 \%$ to $17 \%$.

The data show behavioural change, with respondents reporting lesser amounts of alcohol consumption during pregnancy than in the pre-pregnancy period.

The percentage of women who consume alcohol during the preimplantation period is alarmingly high, over $90 \%$. This behaviour poses a substantial risk to the embryo, especially at its earliest stage of development.

Action should be immediately taken to reduce the consumption of alcohol by young people and women of reproductive age.

\section{ACKNOWLEDGMENTS}

Editors would like to acknowledge the invaluable assistance of Mr. Scott Thompson in the preparation of the final version of this article.

\section{DISCLOSURES}

Authors report no conflict of interest.

\section{References}

1. Chudley AE, Conry J, Cook JL, et al. Fetal alcohol spectrum disorder: Canadian guidelines for diagnosis. CMAJ 2005; 172 (5 Suppl): S1-S21.

2. O'Leary CM. Fetal alcohol syndrome: diagnosis, epidemiology, and developmental outcomes. J Paediatr Child Health 2004; 40: 2-7.

3. Cheng D, Kettinger L, Uduhiri K, et al. Alcohol consumption during pregnancy: prevalence and provider assessment. Obstet Gynecol 2011; 117: 212-217.

4. World Health Organization. Standard drink measures, in grams per unit data by country. Available from: http://apps.who.int/ gho/data/view.main.54180 (accessed: 12 December 2016).

5. Australian Government. The Departament of Health. Standard drinks guide. Available from: http://www.alcohol.gov.au/internet/alcohol/publishing.nsf/Content/drinksguide-cnt (accessed: 11 January 2016).

6. Scheuplein R, Charnley G, Dourson M. Differential sensitivity of children and adults to chemical toxicity. I. Biological basis. Regul Toxicol Pharmacol 2002; 35: 429-447. 
7. Chaudhuri JD. Alcohol and the developing fetus - a review. Med Sci Monit 2000; 6: 1031-1041.

8. International Agency for Research on Cancer. Re-evaluation of some organic chemicals, hydrazine and hydrogen peroxide. Proceedings of the IARC Working Group on the Evaluation of Carcinogenic Risks to Humans. Lyons, France, 17-24 February 1998. IARC Monogr Eval Carcinog Risks Hum 1999; 71: 1-315.

9. Armant DR, Saunders DE. Exposure of embryonic cells to alcohol: contrasting effects during preimplantation and postimplantation development. Semin Perinatol 1996; 20: 127-139.

10. Halsted CH, Villanueva J, Chandler CJ, et al. Ethanol feeding of micropigs alters methionine metabolism and increases hepatocellular apoptosis and proliferation. Hepatology 1996; 23: 497-505.

11. Shukla SD, Velazquez J, French SW, et al. Emerging role of epigenetics in the actions of alcohol. Alcohol Clin Exp Res 2008; 32: 1525-1534.

12. Barak AJ, Beckenhauer HC, Tuma DJ, et al. Effects of prolonged ethanol feeding on methionine metabolism in rat liver. Biochem Cell Biol 1987; 65: 230-233.

13. Halsted $\mathrm{CH}$, Villanueva JA, Devlin AM, et al. Metabolic interactions of alcohol and folate. J Nutr 2002; 132 (8 Suppl): 2367S-2372S

14. Finkelstein JD, Cello JP, Kyle WE. Ethanol-induced changes in methionine metabolism in rat liver. Biochem Biophys Res Commun 1974; 61: 525-531.

15. Hamilton DA, Kodituwakku P, Sutherland RJ, et al. Children with Fetal Alcohol Syndrome are impaired at place learning but not cued-navigation in a virtual Morris water task. Behav Brain Res 2003; 143: 85-94.

16. Berman RF, Hannigan JH. Effects of prenatal alcohol exposure on the hippocampus: spatial behavior, electrophysiology, and neuroanatomy. Hippocampus 2000; 10: 94-110.

17. National Center on Birth Defects and Developmental Disabilities, Centers for Disease Control and Prevention, Department of Health and Human Services. Fetal alcohol syndrome: Guidelines for referral and diagnosis. Atlanta 2004. Available from: https://www.cdc.gov/ncbddd/fasd/documents/FAS_guidelines_accessible.pdf (accessed: 11 November 2016).

18. Mirkes PE (ed.). Congenital malformations surveillance report: A report from the national birth defects prevention network. Birth Defects Research 2003; 67: 617-624.

19. Jones KL, Smith DW, Ulleland CN, et al. Pattern of malformation in offspring of chronic alcoholic mothers. Lancet 1973; 1: 1267-1271.

20. Escobar LF, Bixler D, Padilla LM. Quantitation of craniofacial anomalies in utero: fetal alcohol and Crouzon syndromes and thanatophoric dysplasia. Am J Med Genet 1993; 45: 25-29.

21. Coulter CL, Leech RW, Schaefer GB, et al. Midline cerebral dysgenesis, dysfunction of the hypothalamic-pituitary axis, and fetal alcohol effects. Arch Neurol 1993; 50: 771-775.

22. Florek E, Billert H, Piekoszewski. Narkotyki i używki w okresie ciąży [Illicit drugs and stimulants during pregnancy]. In: Medycyna matczyno-płodowa [Maternal and fetal medicine]. Bręborowicz GH (ed.). PZWL, Warsaw 2012; 511-520.

23. Elliott EJ, Bower C. Alcohol and pregnancy: the pivotal role of the obstetrician. Aust N Z J Obstet Gynaecol 2008; 48: 236-239.
24. Center for Disease Control and Prevention. PRAMS. Available from: http://www.cdc.gov/prams (accessed: 10 November 2016).

25. Wojtyla C, Wojtyla-Buciora P. Polish Pregnancy-related Assessment Monitoring System (Pol-PrAMS): research on lifestyle health behavior of Polish women during gestation - study design. J Health Inequal 2016; 2: 185-191.

26. Wojtyła A, Kapka-Skrzypczak L, Diatczyk J, et al. Alcohol-related Developmental Origin of Adult Health - population studies in Poland among mothers and newborns (2010-2012). Ann Agric Environ Med 2012; 19: 365-377.

27. Biliński P, Wojtyła A. Zdrowie prokreacyjne w świetle badania zachowań ryzykownych u kobiet w ciąży [Reproductive health in light of the study of risky health behaviors in pregnant women]. In: Zdrowie publiczne i polityka ludnościowa. Tom 2 [Public health and population policy. Volume 2]. Szybmborski J (ed.). The Government Population Council, Warsaw 2012; 131-151.

28. Ebrahim SH, Anderson Ak, Floyd RL. Alcohol consumption by reproductive-aged women in the USA: An update on assessment, burden and prevention in the 1990s. Prenat Neonat Med 1999; 4: 419-430.

29. Hanson JW, Streissguth AP, Smith DW. The effects of moderate alcohol consumption during pregnancy on fetal growth and morphogenesis. J Pediatr 1978; 92: 457-460.

30. Wilsnack SC, Wilsnack RW, Hiller-Sturmhofel S. How women drink: Epidemiology of women's drinking and problem drinking. Alcohol Health Res World 1994; 18: 173-181.

31. Center for Disease Control and Prevention. Alcohol use among women of childbearing age - United States. MMWR 2002; 51 : 273-276.

32. Bonati M, Fellin G. Changes in smoking and drinking behaviour before and during pregnancy in Italian mothers: implications for public health intervention. ICGDUP (Italian Collaborative Group on Drug Use in Pregnancy). Int J Epidemiol 1991; 20: 927-932.

33. Lee SH, Shin SJ, Won SD, et al. Alcohol use during pregnancy and related risk factors in Korea. Psychiatry Investig 2010; 7: 86-92.

34. Kesmodel U. Binge drinking in pregnancy - frequency and methodology. Am J Epidemiol 2001; 154: 777-782.

35. Kesmodel U, Kesmodel PS, Larsen A, et al. Use of alcohol and illicit drugs among pregnant Danish women, 1998. Scand J Public Health 2003; 31: 5-11.

36. Chambers CD, Kavteladze L, Joutchenko L, et al. Alcohol consumption patterns among pregnant women in the Moscow region of the Russian Federation. Alcohol 2006; 38: 133-137.

37. PARPA. Wzory konsumpcji alkoholu w Polsce [Alcohol consumption patterns in Poland], 2008. Available from: http:// www.parpa.pl/download/wyniki\%20badania\%20wzory\%20 konsumnpscji\%202008_\%202\%20metody_poprMFdoc.pdf (accessed: 11 November 2016).

38. Moskalewicz J. Problemy zdrowia prokreacyjnego związane z konsumpcją alkoholu [Alcohol-related procreation health problems]. In: Zdrowie kobiet w wieku prokreacyjnym 15-49 lat. Program Narodów Zjednoczonych ds. Rozwoju [Health of women of reproductive age, aged 15 to 19. United Nations Development Program]. Niemiec T (ed.). Warsaw 2007; 70-72. 
39. Ethen MK, Ramadhani TA, Scheuerle AE, et al. National Birth Defects Prevention Study. Alcohol consumption by women before and during pregnancy. Maternal Child Health J 2009; 13: $274-285$.

40. Kesmodel U, Wisborg K, Olsen SF, et al. Moderate alcohol intake in pregnancy and the risk of spontaneous abortion. Alcohol Alcohol 2002; 37: 87-92.

41. Kesmodel U, Wisborg K, Olsen SF, et al. Moderate alcohol intake during pregnancy and the risk of stillbirth and death in the first year of life. Am J Epidemiol 2002; 155: 305-312.

42. Schenker S, Becker HC, Randall CL, et al. Fetal alcohol syndrome: current status of pathogenesis. Alcohol Clin Exp Res 1990; 14: 635-647.

43. Dzielska A. Picie Alkoholu [Alcohol consumption]. In: Zdrowie i zachowania zdrowotne młodzieży szkolnej w Polsce na tle wybranych uwarunkowań socjodemogracznych. Wyniki badań HBSC 2014 [Health and health behaviour of school-children in Poland in the light of sociodemographic determinants. Results of HBSC 2014 studies]. Mazur J (ed.). The Institute of Mother and Child, Warsaw 2015; 176-186.

\section{AUTHORS' CONTRIBUTIONS}

CW, AW collected and analysed data, prepared the research concept of the publication, revised the paper and finally approved it.

$\mathrm{CW}$ wrote the article. 